This document is confidential and is proprietary to the American Chemical Society and its authors. Do not copy or disclose without written permission. If you have received this item in error, notify the sender and delete all copies.

\title{
Studies of dynamic binding of amino acids to TiO2 nanoparticle surfaces by Solution NMR and Molecular Dynamics Simulations
}

\begin{tabular}{|r|l|}
\hline Journal: & Langmuir \\
\hline Manuscript ID & la-2020-012568.R2 \\
\hline Danuscript Type: & Article \\
\hline Author: & 20 -Jul-2020 \\
\hline Complete List of Authors: & $\begin{array}{l}\text { xue, mengjun; University of Washington, Department of Chemistry } \\
\text { Sampath, Janani; University of Washington , } \\
\text { Gebhart, Rachel; University of Washington Seattle Campus, Chemistry } \\
\text { Haugen, Havard; Universitetet i Oslo, Institute for Clinical Dentistry, } \\
\text { Department Biomaterials } \\
\text { Lyngstadaas, Stale ; University of Oslo, Department for Biomaterials, } \\
\text { Faculty for Odontology } \\
\text { Pfaendtner, Jim; University of Washington, Chemical Engineering } \\
\text { Drobny, Gary; University of Washington, Chemistry }\end{array}$ \\
\hline
\end{tabular}

\section{SCHOLARONE" Manuscripts}




\title{
Studies of dynamic binding of amino acids to $\mathrm{TiO}_{2}$ nanoparticle surfaces by Solution NMR and Molecular Dynamics Simulations
}

\author{
Mengjun Xue, ${ }^{1}$ Janani Sampath, ${ }^{2}$ Rachel N. Gebhart, ${ }^{1}$ Havard J. Haugen, ${ }^{3}$ \\ S. Petter Lyngstadaas, ${ }^{3}$ Jim Pfaendtner, ${ }^{2}$ Gary Drobny ${ }^{1, *}$
}

1. Department of Chemistry, University of Washington Box 351700, Seattle, Washington 98195, United State

2. Department of Chemical Engineering, University of Washington Box 351700, Seattle, Washington 98195, United States

3. Department for Biomaterials, Faculty for Odontology, University of Oslo, PO Box 1109 Blindern, NO-0317 Oslo, Norway

\begin{abstract}
Adsorption of biomolecules onto material surfaces involves a potentially complex

mechanism where molecular species interact to varying degrees with a heterogeneous

material surface. Surface adsorption studies by atomic force microscopy (AFM), Sum

Frequency Generation (SFG) spectroscopy, and solid state NMR (ssNMR), detect the
\end{abstract}


structures and interactions of biomolecular species that are bound to material surfaces and which, in the absence of a solid liquid interface, do not exchange rapidly between surface-bound forms and free molecular species in bulk solution. Solution NMR has the potential to complement these techniques by detecting and studying transiently bound biomolecules at the liquid-solid interface. Herein we show that dark-state exchange saturation transfer (DEST) NMR experiments on gel-stabilized $\mathrm{TiO}_{2}$ nanoparticle (NP) samples detect several forms of biomolecular adsorption onto titanium (IV) oxide surfaces. Specifically, we use the DEST approach to study the interaction of amino acids arginine (Arg), lysine (Lys), leucine (Leu), alanine (Ala), and aspartic acid (Asp) with $\mathrm{TiO}_{2}$ rutile nanoparticle surfaces. Whereas Leu, Ala, and Asp display only a single weakly interacting form in the presence of $\mathrm{TiO}_{2}$ nanoparticles, Arg and Lys displayed at least two distinct bound forms: a species that is surface bound and retains a degree of reorientational motion, and a second more tightly bound form characterized by broadened DEST profiles upon addition of $\mathrm{TiO}_{2}$ nanoparticles. Molecular Dynamics simulations indicate different surface bound states for both Lys and Arg depending on the degree of $\mathrm{TiO}_{2}$ surface hydroxylation, but only a single bound state for Asp regardless of the degree 
of surface hydroxylation, in agreement with results obtained from analysis of DEST

profiles.

\section{INTRODUCTION}

The interaction of biomolecules with titanium (IV) oxide $\left(\mathrm{TiO}_{2}\right)$ nanoparticles (NP's) is a topic relevant to a variety of fields including medical and dental implants, biosensors, chromatography, and catalysis. ${ }^{1-12}$ Fundamental to our understanding of how biomolecules interact with $\mathrm{TiO}_{2}$ NP's is knowledge of the structures of these molecules at NP surfaces. However, detailed structural information of surface-adsorbed peptides is only now emerging, ${ }^{13-15}$ and the nature of protein-mineral surface interactions has yet to be clarified even for small monomeric amino acids and small mineral-binding peptides. Methods used to detect and characterize surfacebound molecular species include Atomic Force Microscopy (AFM), ${ }^{16-18}$ Sum Frequency Generation (SFG) Spectroscopy, ${ }^{19-20}$ Solid State NMR (ssNMR), ${ }^{21}$ Saturation Transfer Difference $\mathrm{NMR}^{22}$ to name a few. These methods detect the presence of partly or entirely immobilized biomolecular species at material surfaces where the amino acid side chains provide points of surface contact.

The mechanism of surface adsorption of biomolecules onto $\mathrm{TiO}_{2} \mathrm{NP}$ 's is complex and may involve, prior to final attachment and immobilization on the surface, formation of biomolecular species that interact with and are only partly immobilized near the NP surface. In addition, the material surface may be heterogeneous, resulting in a variation in binding affinity over the surface and in multiple forms of bound species. Because they are the monomeric constituents of proteins, adsorption of amino acids onto metallic and oxide surfaces has been widely studied. Although 
thermodynamic studies of lysine ${ }^{23,24}$ and histidine ${ }^{25}$ adsorption onto $\mathrm{TiO}_{2} \mathrm{NP}^{\prime}$ 's fitted data using a simple Langmuir model, which assumes a single affinity constant and a single independently bound form, spectroscopic studies have identified more complex scenarios for adsorption of some amino acids on $\mathrm{TiO}_{2}$ NP's. A IR spectroscopic study of the binding of glutamic acid and aspartic acid to $\mathrm{TiO}_{2}$ NP's found that while at all $\mathrm{pH}$ 's aspartic acid binds in a single form, glutamic acid binds in at least two forms. ${ }^{26} \mathrm{~A}$ very recent thermodynamic study of the adsorption of L-amino acids onto $\mathrm{TiO}_{2}$ NP's found that the $\mathrm{BET}$ model fits the binding of most amino acids to $\mathrm{TiO}_{2}$, with the binding being endothermic and thus entropy driven. ${ }^{27}$ In the same study computations showed surface interactions via hydrogen bonding between the $\alpha$-ammonium group and surface hydroxyl oxygens, while basic and acid amino acids can also interact with the surface via their side chains. In view of the complex nature of amino acid and peptide adsorption onto $\mathrm{TiO}_{2} \mathrm{NP}^{\prime}$, it is useful to apply experimental techniques that can detect several types of adsorbed species, under the same sample conditions. Dark-state exchange saturation transfer (DEST) NMR experiments have provided thermodynamic and kinetic information on the binding of small proteins to aggregates and large molecular machines. ${ }^{28-30}$ DEST relies on slow exchange of nuclear spins between sites with very different values of the transverse relaxation rate $R_{2}$, as would occur for example when a freely tumbling molecular species in solution with a small $\mathrm{R}_{2}$, adsorbs onto a $\mathrm{TiO}_{2} \mathrm{NP}$ surface with the resulting immobilized species displaying a much larger $R_{2}$. In addition to $R_{2}$ values for free and bound molecular species, simulation of the DEST saturation profile yields further information, including the relative 
populations of the free and adsorbed species, and the kinetic constants that quantify the rate of exchange between free and adsorbed species. In an initial demonstration of this approach, Egner et al. ${ }^{31}$ applied ${ }^{1} \mathrm{H}$ DEST and relaxation dispersion (RD) to the study of the adsorption of phenol and cholic acid onto cerium oxide NP's. By direct solution of the BlochMcConnell equations and subsequent simulation of the ${ }^{1} \mathrm{H}$ DEST saturation profiles, Egner et al showed that while cholic acid adsorbs from bulk solution to a weakly-bound state that does not constitute a rigid adduct with the NP, phenol adsorption proceeds via an intermediate, weakly bound species to a state that is rigidly bound to the NP surface. Therefore, the Egner et al. study afforded not only populations of free and bound species, but also a kinetic mechanism for the adsorption process.

MD simulations have also provided valuable insights into the binding mechanism

of amino acids and their analogs on the surface of $\mathrm{TiO}_{2} \cdot{ }^{32-36}$ Bowen et al. found that the adsorption of amino acids with polar sidechains on a negative rutile (110) surface is a function of both backbone and sidechain binding. ${ }^{32}$ Walsh and coworkers studied the binding of arginine, aspartate and lysine analogs on two variants of the rutile interface negative and neutral; they report that the arginine analog adsorbed the strongest to both interfaces, followed by the lysine and aspartate analogs. ${ }^{35,36}$ Recently, Schelokov et al. described the adsorption of amino acids on nanocrystalline anatase particles using QSPR 
and MD simulations, they find that the binding occurs primarily through the formation of two - three hydrogen bonds via sidechain or backbone groups that are charged. ${ }^{27}$ In this paper we apply ${ }^{1} \mathrm{H}$ DEST techniques to the study of the adsorption of small biomolecules, i.e. amino acids, to $\mathrm{TiO}_{2}$ rutile nanocrystals. Application of DEST methods to studying the binding of biomolecules to mineral surfaces has the same requirements detailed in the study of Egner et al. ${ }^{31}$ Namely, the NMR-visible molecules (i.e. the free, unbound molecules) and the NMR-invisible molecules (i.e. the surface-bound molecules) have to remain homogeneously suspended in the NMR sample throughout the NMR measurement period. We followed the procedure described in Egner et al. and used 1 wt $\%$ agarose to prevent nanoparticle sedimentation. By introducing $\mathrm{TiO}_{2}$ nanocrystals into agarose gel suspensions, we investigated the binding of arginine (Arg), lysine (Lys), leucine (Leu), aspartate (Asp), and alanine (Ala) amino acid. We chose amino acids as model systems for initial study because they contain the same side chain functional groups used by peptides and proteins to adsorb onto $\mathrm{TiO}_{2} \mathrm{NP}$ surfaces, ${ }^{16-18}$ yet their small size limits the number of surface-bound forms that may be present. Lorentzian deconvolution of ${ }^{1} \mathrm{H}$ DEST saturation profiles indicate for Arg and Lys the existence of 
multiple forms of adsorbed molecules, distinguished by differing degrees of residual molecular motion. Simulation of the ${ }^{1} \mathrm{H}$ DEST profiles by direct solution of the BlochMcConnell equation provides quantitative information including relative populations of free and adsorbed species as well as kinetic constants that quantify rate of exchange between free and adsorbed species. Finally, molecular dynamics simulations also demonstrate the existence of multiple binding states of Arg and Lys on rutile surfaces, and investigate the role played by surface hydroxylation in mediating these interactions.

Overall this paper demonstrates how the application DEST NMR experiments and MD calculations in a concerted fashion can elucidate both thermodynamic and kinetic aspects of the adsorption of biomolecules at liquid-solid interfaces.

\section{EXPERIMENTAL}

Materials. Amino acids alanine, leucine, arginine, lysine, and aspartic acid were purchased from Sigma-Aldrich (St. Louis, MO) and used without purification. $\mathrm{TiO}_{2}$ (product number 637262; rutile titanium (IV) oxide nanopowder with a reported particle size $<100 \mathrm{~nm}$ ) nanoparticles were purchased from Sigma-Aldrich (St. Louis, MO) with a BET measured surface area of $28.6 \mathrm{~m}^{2} / \mathrm{g}$. Agarose were purchased from Sigma Aldrich and used without further purification. Deuterated solvents were purchased from Sigma Aldrich and used without further purification. 
Preparation of NMR samples. $10 \mathrm{mM}$ Amino acids (Arg, Lys, Leu, Pro, Asp, and Ala) NMR samples were prepared in $20 \mathrm{mM}$ phosphate buffer $\mathrm{pD} 7$ with $99.9 \% \mathrm{D}_{2} \mathrm{O}$.

Samples without $\mathrm{TiO}_{2}$ nanopowder in the presence of agarose gel were prepared by mixing $1 \%$ $w / w$ agarose in $20 \mathrm{mM}$ phosphate buffer $\left(\mathrm{pD} 7,99.9 \% \mathrm{D}_{2} \mathrm{O}\right)$. The mixture was placed in a boiling water bath for $5 \mathrm{~min}$, then removed to a block heater to cool. When the temperature of equilibrated to between 50 and $60^{\circ} \mathrm{C}$, amino acid solution was added, resulting in a final concentration of 10 mM. The warm solution was transferred to an NMR tube and allowed to cool at room temperature.

Samples that contained $\mathrm{TiO}_{2}$ nanopowder in the presence of gel were prepared by mixing $1 \% \mathrm{w} / \mathrm{w}$ $\mathrm{TiO}_{2}$ nanopowder and agarose in $20 \mathrm{mM}$ phosphate buffer ( $\mathrm{pD} 7,99.9 \% \mathrm{D}_{2} \mathrm{O}$ ). The mixture was vortex mixed and sonicated for $5 \mathrm{~min}$, then placed in a boiling water bath for $5 \mathrm{~min}$. The sample was then removed to a block heater and its internal temperature allowed to equilibrate between 50$60^{\circ} \mathrm{C}$. The respective amino acid solution was added, resulting in a final concentration of $10 \mathrm{mM}$. The warm solution was transferred to an NMR tube and allowed to cool to room temperature.

NMR spectroscopy. The NMR measurements were performed at $25{ }^{\circ} \mathrm{C}$ on a Bruker Avance III $700 \mathrm{MHz}$ NMR instrument equipped with a $5 \mathrm{~mm}$ Broadband Observe (BBO) probe. ${ }^{1} \mathrm{H}$-DEST experiments were measured at multiple saturation fields $(50 \mathrm{~Hz}, 100 \mathrm{~Hz}, 150$ $\mathrm{Hz}, 200 \mathrm{~Hz}, 250 \mathrm{~Hz}$ and $300 \mathrm{~Hz}$ ) using a ${ }^{1} \mathrm{H}$ DEST pulse scheme. ${ }^{31} 1 \mathrm{D}{ }^{1} \mathrm{H}$ spectra were recorded in steps of 0.25 or $2.5 \mathrm{ppm}$ with the position of the ${ }^{1} \mathrm{H}$ B1 field ranging from $-100 \mathrm{ppm}$ to +100 ppm, and an offset of $-100 \mathrm{ppm}$ was used for normalization. The saturation field was applied for 1 $\mathrm{s}$, and a repetition delay of $3 \mathrm{~s}$. NMR spectra were processed using Topspin 4.0.2 and Mnova NMR (http://mestrelab.com/software/mnova/nmr/). Spectra were analyzed using Bruker dynamics 
center (https://www.bruker.com/products/mr/nmr/nmr-software/software/dynamicscenter/overview.html.) and Mnova NMR.

Analysis of data. Data were processed with Peak Analyzer in OriginPro (OriginLab Corporation, Northampton, MA, USA). Z-spectra (I/I $\mathrm{I}_{0}$ (or DEST profile) were normalized by the signal with RF irradiation at $-100 \mathrm{ppm}\left(\mathrm{I}_{0}\right)$. For the conventional fitting method, multi-pool Lorentzian fitting of the Z-spectra was applied to estimate the DEST effects from different pools. ${ }^{37-39}$ Briefly, the inverted Z-spectra $\left(1-\mathrm{I} / \mathrm{I}_{0}\right)$ were fitted as the sum of multiple Lorentzian functions with the following equation:

$$
1-\frac{I}{I_{0}}=\sum_{i=1}^{N} \frac{A_{i}}{1+4\left(\frac{\omega-\omega_{i}}{\sigma_{i}}\right)^{2}}
$$

where $\omega$ is the frequency offset from the interest resonance, $A_{i}, \omega_{i}$, and $\sigma_{i}$ are the amplitude, frequency offset and linewidth of the DEST peak for the $\mathrm{i}^{\text {th }}$ proton pool respectively. In the DEST phantom, we employed a four-pool or five-pool Lorentzian model of magnetization transfer (MT), and Nuclear Overhauser enhancement (NOE) effects from bound water and/or nearby hydrogens in molecules. ${ }^{40-41}$

Global fitting was accomplished with a homogenous form of McConnell equations using Matlab code DESTfit (https://spin.niddk.nih.gov/clore/Software/software.html). ${ }^{28}$ A single spin was assumed to be in exchange between an observable free state with low $R_{2}$ and a two types of bound forms with larger $R_{2}$ values $(A<==>$ the mixture of $B$ and $C) .{ }^{28}$ The cross-relaxation between two spins was incorporated in the McConnell model: the cross- 
relaxation rate $\sigma_{A}$ between $H_{1}$ (the observed signal) and $H_{2}$ (coupled with $H_{1}$ by cross relaxation) in the free amino acid is assumed to be $-0.5 \mathrm{~s}^{-1}$, and the cross-relaxation rate $\sigma_{B}$ between $H_{1}$ and $H_{2}$ of amino acid bound on particle is assumed to be $-500 \mathrm{~s}^{-1} .28$

Molecular Dynamics Calculations The effects of molecular (non-hydroxylated $\mathrm{TiO}_{2}$ ) and dissociated (hydroxylated $\mathrm{TiO}_{2}$ ) surface water were investigated for two variants of the rutile (110), using the force field developed by Předota et al. ${ }^{42}$ The surface dimensions are approximately $5.5 \times 5.3 \times 1.8 \mathrm{~nm}^{3}$, and both surfaces are negatively charged with a charge density of $-0.103 \mathrm{C} / \mathrm{m}^{2}$, corresponding to a $\mathrm{pH}$ of 8 . Three amino acids were chosen for this study - aspartic acid (Asp), lysine (Lys), and arginine (Arg); in the $\mathrm{pD}$ range of 7.5-8.0, the charges of the amino acid sidechains are $-1,+1$ and +1 , respectively. To remain comparable with the ${ }^{1} \mathrm{H}$ NMR experiment, amino acid termini have a deprotonated carboxylate group and a protonated amine group. The amino acids were modeled using the CHARMM36 forcefield. ${ }^{43}$ A water slab 8nm thick consisting of $\sim 7500$ molecules of SPC/E water was added above the surface. System equilibration was carried out using a Dona dio-Bussi-Parrinello ${ }^{44}$ and a Parrinello-Rahman ${ }^{45}$ barostat to maintain a temperature and pressure of $300 \mathrm{~K}$ and 1 bar, respectively. After equilibrating the system at 1 bar and $300 \mathrm{~K}$, well-tempered metadynamics ${ }^{46}$ was employed to calculate binding free energy profiles by biasing the vertical distance of the peptide from the surface (see Supporting Information for details). Simulations were performed using GROMACS 5.1.2, ${ }^{47}$ along with the PLUMED plugin ${ }^{48}$ for enhanced sampling.

RESULTS AND DISCUSION 


\section{${ }^{1} \mathrm{H}$ DEST NMR Studies of the interactions of amino acids Arg, Lys, Asp, Leu and Ala with}

$\mathrm{TiO}_{2}$ NPs in Agarose Gels. The addition of $\mathrm{TiO}_{2}(1 \mathrm{wt} \%)$ to a $10 \mathrm{mM}$ amino acid solution in 99.9\% $\mathrm{D}_{2} \mathrm{O}$ resulted in extensive line broadening of the NMR resonances in all cases (Figure 1, and Figure S1), thus indicating that Arg, Lys, Asp, Leu and Ala all interact with $\mathrm{TiO}_{2}$ and exchange between a free and a bound state. A lesser degree of peak broadening in observed upon the addition of agarose gel to the sample, indicating that the amino acids are weakly interacting with the matrix, but retain the ability to diffuse and tumble freely.

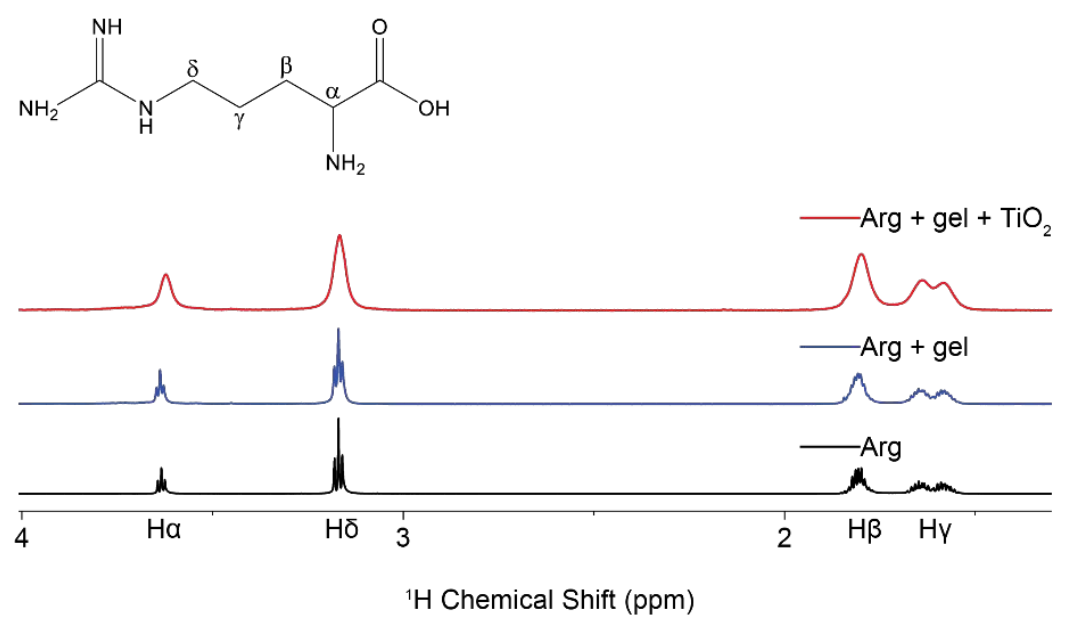

Figure 1. ${ }^{1} \mathrm{H}$ proton spectra of arginine neat (black), suspended in agarose gel (blue), and exposed to $\mathrm{TiO}_{2}$ nanoparticles in the presence of agarose gel (red). Addition of $\mathrm{TiO}_{2}$ to the sample creates distinct peak broadening not observed in the other two spectra, indicative of interactions with a slow tumbling object.

In DEST NMR experiments slow exchange and by inference contact with NP surfaces, is indicated by broadening of the DEST saturation profile upon addition of agarose gel and $\mathrm{TiO}_{2}$ NPs. Figure 2 shows the ${ }^{1} \mathrm{H}$ DEST profiles of side chain protons for five monomeric amino acids (Arg, Lys, Leu, Asp, and Ala): 1) free in solution (10mM), 2) in the presence of agarose gel, and 3) in the presence of $\mathrm{TiO}_{2} \mathrm{NPs}$ and agarose gel. These amino acids 
were chosen for their appearance in the hexamer peptide TBP-6, which has been shown to bind strongly to rutile $\mathrm{TiO}_{2} \cdot{ }^{16}$ Mutation studies of the peptide have suggested that the three polar residues (Arg, Lys, and Asp) are involved in surface adhesion, while further studies have suggested that non-polar residues may also play a role in surface interactions. ${ }^{32-36}$ In the absence of $\mathrm{TiO}_{2}$ NP's the DEST saturation profiles for $\mathrm{H} \varepsilon$ of Lys (Figure $2 \mathrm{~b}$ ) and $\mathrm{H} \delta$ of $\mathrm{Arg}$ (Figure $2 \mathrm{a}$ ) are narrow and confined to $<1 \mathrm{ppm}$ region about the respective resonance frequencies. In both cases there is a slight broadening of the saturation profile upon addition of agarose gel (Figures $2 a$ and $2 b$ ), indicating weak interactions of these basic amino acids with the gel. Upon addition of $\mathrm{TiO}_{2} \mathrm{NPs}$, the saturation profiles of both Arg and Lys become broadened and display broad "wings" indicative of slow exchange between the free state of the amino acid and a "dark", i.e. surface-bound state, with a very large $R_{2}$. The larger broadening of the Arg DEST profile upon $\mathrm{TiO}_{2}$ addition suggests that Arg has a greater affinity of binding to the nanoparticles than Lys. 
Figure 2c-e show analogous DEST saturation profiles for $\mathrm{H} \beta$ of Asp, $\mathrm{H} \delta$ of Leu, and $\mathrm{H} \beta$ of Ala respectively. In the three cases there is no broadening of the saturation profile upon addition of agarose gel (Figure 2c-d), indicating no interactions of these amino acids with the matrix. Interestingly, the Asp monomer as well as the nonpolar amino acids do not show broad "wings" in their DEST profiles upon addition of $\mathrm{TiO}_{2} \mathrm{NPs}$, indicating that these individual amino acid monomers retain considerable re-orientational degrees of freedom upon addition of $\mathrm{TiO}_{2} \mathrm{NPs}$ and as a result have much smaller R2 values than is the case with Arg and Lys.

(a)

(b)

(c)

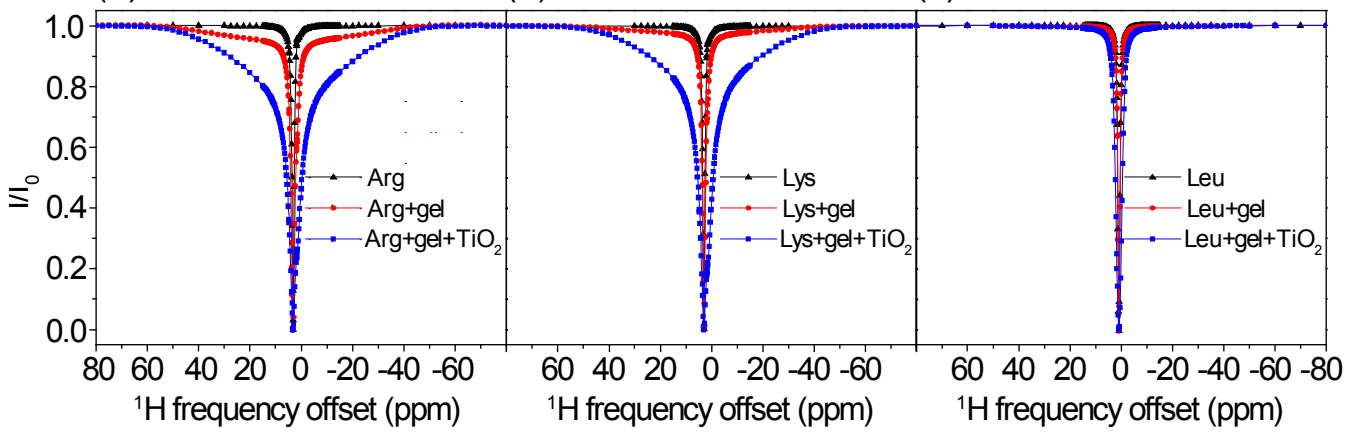

(d)

(e)

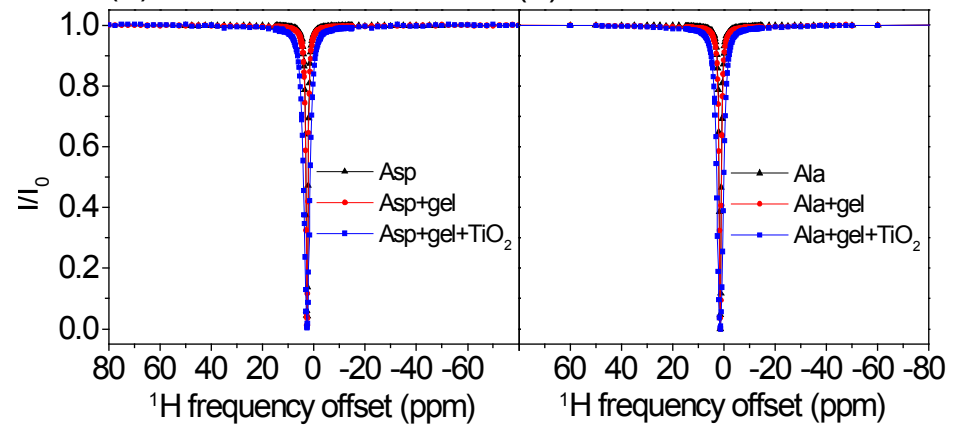

Figure

2. ${ }^{1} \mathrm{H}$ DEST profiles for $\mathrm{H} \delta$ of $10 \mathrm{mM}$ Arg (a), He of $10 \mathrm{mM}$ Lys (b), H $\delta$ of $10 \mathrm{mM} \mathrm{Leu} \mathrm{(c),} \mathrm{H} \beta$ of 
Asp (d), and $\mathrm{H} \beta$ of $10 \mathrm{mM}$ Ala (e) neat (black), with $1 \% w / w$ agarose gel (red), and with $1 \% w / w$ agarose gel and $1 \% w / w \mathrm{TiO}_{2}$ nanoparticles (blue). Slight peak broadening of the DEST profile upon addition of agarose gel for Arg and Lys (a-b) indicates a weak interaction between the agarose gel and the amino acids, and broadening upon addition to $\mathrm{TiO}_{2}$ indicates an interaction with the oxide. In all figures $\mathrm{B} 1=300 \mathrm{~Hz}$.

In the case of Arg and Lys the ${ }^{1} \mathrm{H}$ DEST profiles in the presence of $\mathrm{TiO}_{2} \mathrm{NPs}$ are asymmetric, indicating presence of spectral features in addition to the direct saturation lines. Information on the origins of the broad asymmetric DEST profiles for Arg (Figure 3) and Lys (Figure S2) may be obtained by a study of the DEST profiles as a function of ${ }^{1} \mathrm{H}$ $\mathrm{B}_{1}$ field strength. Figure 3 shows ${ }^{1} \mathrm{H}$ DEST profiles for the $\mathrm{H} \delta$ proton of Arg: (a) free in 10 mM solution; (b) $10 \mathrm{mM}$ concentration in agarose gel; and (c) $10 \mathrm{mM}$ concentration in agarose gel and in the presence of $\mathrm{TiO}_{2} \mathrm{NPs}$, for $\mathrm{B}_{1}$ saturation fields ranging from 50-300 Hz. In all three figures a partial source of the asymmetry is traced in part to a line at a chemical shift of $1.68 \mathrm{ppm}$. In Figure 3a this is the small feature out of phase with the direct saturation line, while in Figure $3 \mathrm{~b}$ and $\mathrm{c}$ the line at $1.68 \mathrm{ppm}$ is in phase with the direct saturation line and is much more intense. This $1.68 \mathrm{ppm}$ line is therefore an NOE to neighboring $\mathrm{H} \beta$ and $\mathrm{H} \gamma$ protons. The fact that the NOE inverts from positive to negative upon addition of gel indicates a slowing of molecular reorientations, and the increase in the NOE intensity upon addition of $\mathrm{TiO}_{2} \mathrm{NPs}$ indicates a further slowing of molecular reorientations due to strong interactions between the amino acid and the $\mathrm{TiO}_{2} \mathrm{NP}$ surface. 
From the line shapes in Figure $3 \mathrm{c}$ at least four components to the ${ }^{1} \mathrm{H}$ DEST saturation profile are discernable: 1) the direct $\mathrm{H} \delta$ saturation component at $3.16 \mathrm{ppm}, 2$ ) the aforementioned NOE to neighboring side chain protons at $1.68 \mathrm{ppm}$, and 3) a component at about $4.73 \mathrm{ppm}$ which is the NOE to the protons of surface-adsorbed water on $\mathrm{TiO}_{2}$ particles; 4) a broad component most clearly observable in the $300 \mathrm{~Hz}$. profile. In the DEST saturation profile of the $\mathrm{H} \delta$ proton of $\operatorname{Arg}$, this broad component is centered at about $3.16 \mathrm{ppm}$ and corresponds to a surface immobilized molecular species. This broad component and strong NOE peak is also observed in the ${ }^{1} \mathrm{H}$ DEST profile for the $\mathrm{H} \varepsilon$ proton of Lys (Figure 2b, and Figure S2), but not in the DEST profiles for the side chain protons in Leu, Asp, or Ala (see Figures 2c-e, Figures S3-S5).

(a)

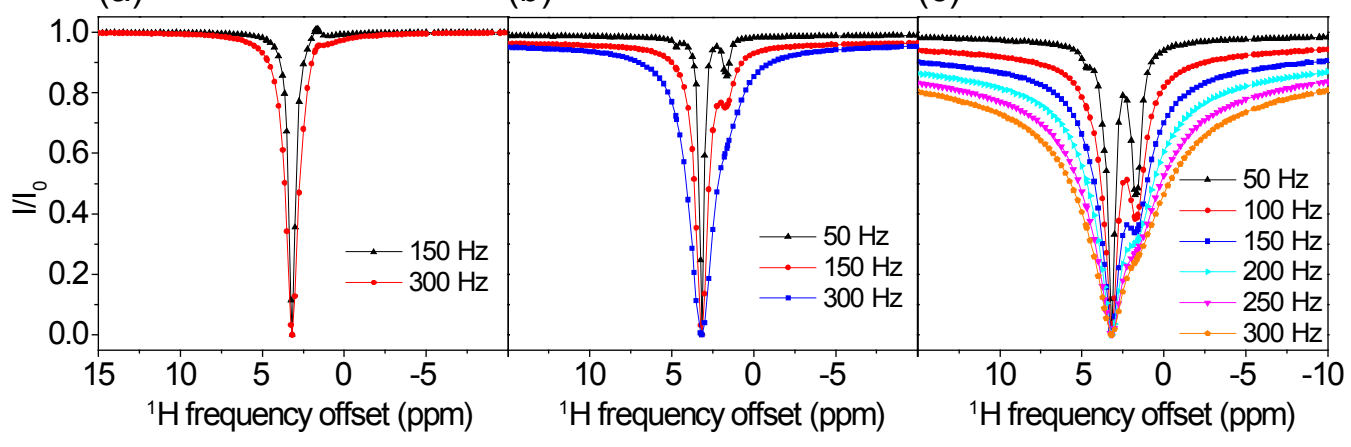

Figure 3. : ${ }^{1} \mathrm{H}$ DEST profiles for $\mathrm{H} \delta$ of $10 \mathrm{mM}$ Arg in the absence of gel (a), in the presence of gel (b), and in the presence of gel and $1 \mathrm{wt} \% \mathrm{TiO} 2$ (c).

To confirm the assumption that ${ }^{1} \mathrm{H}$ DEST profiles for Arg in Figure 3 are interpreted in terms of four spectral components, inverted ${ }^{1} \mathrm{H}$ DEST saturation profiles of Arg (i.e. 1-I/I $\mathrm{I}_{0}$ ) were fitted to Equation 1 for $\mathrm{B}_{1}=50-300 \mathrm{~Hz}$. as described in the data analysis section (Figure $4 \mathrm{a}-\mathrm{c}$ and Table S1-S3). It was assumed that the chemical shifts $\omega_{i}$ were constant for all $B_{1}$ values while $A_{i}$ and $\sigma_{i}$ were varied. As expected, the intensity of the NOE peaks and broad "wing" components 
are enhanced with increasing $B_{1}$ saturation power, although the NOE peak intensities shows relatively less sensitivity to $B_{1}$ saturation power than the broad "wing" components (Table S1-S3). Several conclusions can be drawn from inspection of the fitted data. First, the good agreement between the fits and the data validate the four-component assumption. Second, the direct saturation line is in phase with the NOEs, i.e. the NOEs are negative. This indicates that Arg is tumbling slowly due to interactions with the NP surface. Third, the negative NOE to water is likely not due to magnetization transfer to bulk water but rather involves water that is bound to the $\mathrm{TiO}_{2} \mathrm{NP}$ surface. Finally, these simulations indicate presence of two bound forms of Arg: a weakly bound form which undergoes slow re-orientational motions and is closely associated with surface water molecules, and an immobilized form. A similar analysis has also been performed on the ${ }^{1} \mathrm{H}$ DEST profil for the $\mathrm{H} \varepsilon$ proton of Lys with similar results (Figure S6).

(a

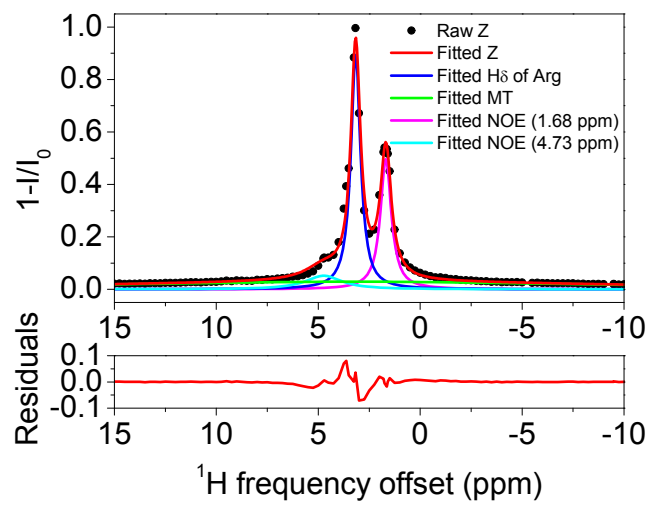

(b

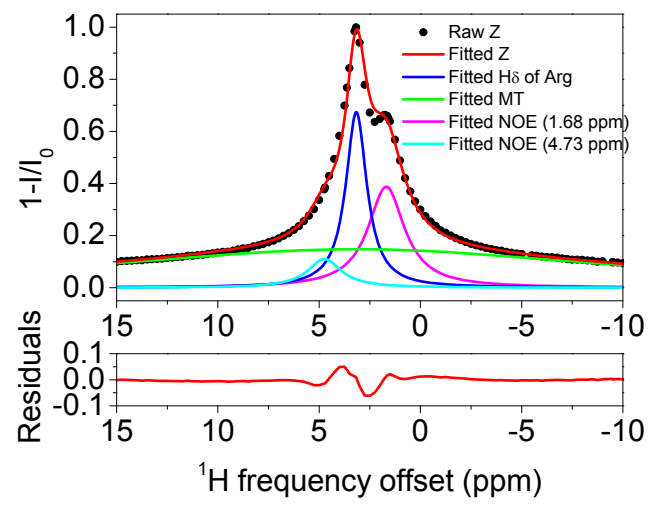

\section{(c}


In contrast to Lys and Arg, the DEST profiles for the side chain protons of Asp, Leu and Ala lack the broad component feature (Figures 2c-2d) and NOE intensities to proximal protons are not observed or are much weaker than is the case for protons in Arg and Lys (Figures S3-S5). These data indicate that Asp, Leu, and Ala do not have multiple forms of surface attached species, these amino acids do not display a strongly surface-attached, immobilized form, and reorientational motions are much faster than is the case for Lys and Arg, indicating much weaker interactions with the $\mathrm{TiO}_{2} \mathrm{NP}$ surface.

To obtain surface adsorption/desorption rates, transverse relaxation $\mathrm{R}_{2}$ rates and the populations of the bulk solution versus adsorbed species, DEST saturation profiles were simulated by numerical solution of the Bloch-McConnell equations. ${ }^{49}$ The multi-Lorentzian fittings to the inverted DEST saturation profiles for $10 \mathrm{mM}$ Arg in the presence of $\mathrm{TiO}_{2} \mathrm{NP}^{\prime}$ 's indicate presence of at least two adsorbed forms of Arg. The simplest kinetic scheme consistent with the simulated 
profiles in Figure 4 is shown in Figure 5. Figure 5 is based on a model where monomeric Arg in bulk solution is in exchange with two physically distinct adsorbed forms: a partially mobile bound form and an immobilized bound form. Adsorption of the amino acid in bulk solution to these bound forms is characterized by the kinetic constant $\mathrm{k}_{\mathrm{on}}$. Desorption from the surface to bulk solution is characterized by $\mathrm{k}_{\mathrm{off}}$, respectively. Exchange between the surface-bound forms was excluded from this model.

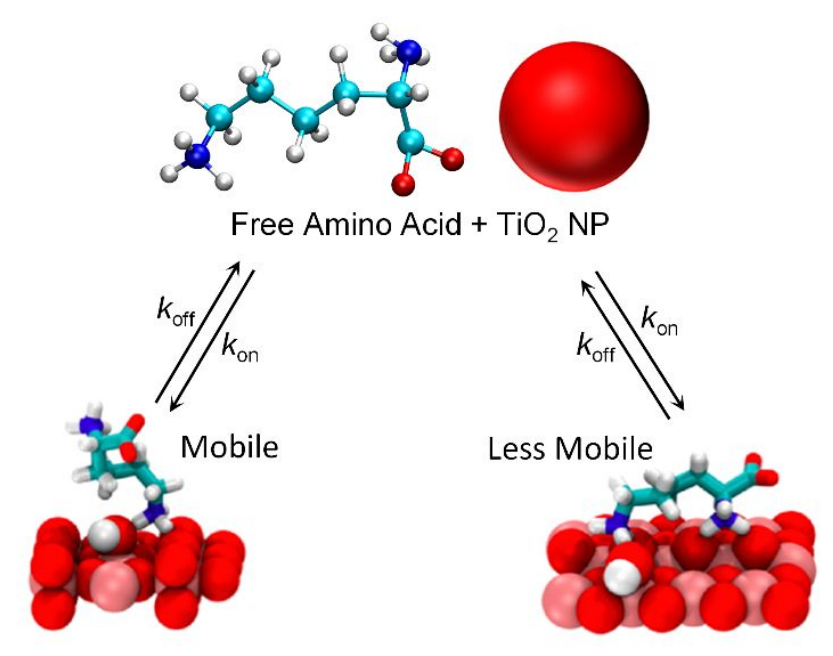

Figure 5. Kinetic Scheme for adsorption of free amino acid onto $\mathrm{TiO}_{2} \mathrm{NP}$ 's. The amino acid in bulk solution adsorbs onto the $\mathrm{TiO}_{2}$ surface in two forms: a partially mobile form and a form that is strongly held on the surface and is more extensively immobilized.

${ }^{1} \mathrm{H}$ DEST profiles of $10 \mathrm{mM}$ Arg in $1 \mathrm{wt} \% \mathrm{TiO}_{2}$ and $1 \mathrm{wt} \%$ agarose at a proton Larmor

frequency of $700 \mathrm{MHz}$ were simulated using the program DESTfit, according to protocols

described in detail in reference 28 and 50. As expected from the multi- Lorentzian fits in

Figure 4 , the DEST profile for $10 \mathrm{mM}$ Arg is fitted best by a model involving exchange 
between the amino acid in bulk solution $A$ and two adsorbed forms $B$ and $C$. The best fit model is shown in Figure 6 and Figure S7, and corresponds to the pseudo-two site exchange described in reference 28 and 50 , where $A$ exchanges with a single kinetic off rate $k_{\text {off, }}$ between a mixture of $\mathrm{B}$ and $\mathrm{C}$ forms. Notably a two-site exchange model where A exchanges with a single bound form did not fit the data well. This case is included as Supplementary Information (Figure S8). A similar analysis of the ${ }^{1} \mathrm{H}$ DEST profile for Lys adsorbed onto $\mathrm{TiO}_{2} \mathrm{NPs}$ is also included in Supplementary Information (Figure S9).

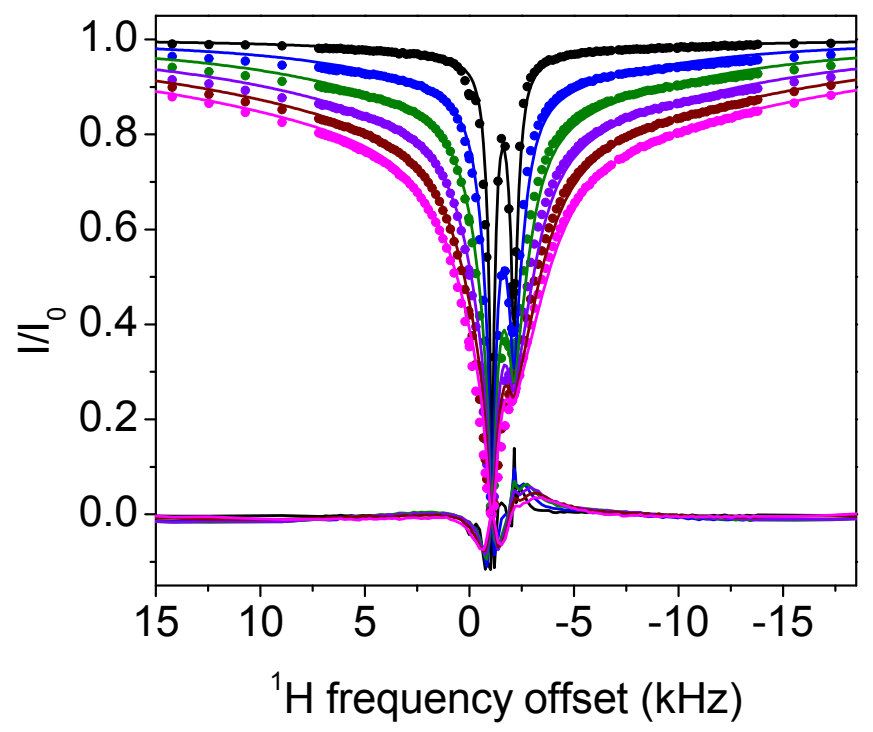

Figure 6. ${ }^{1} \mathrm{H}$ DEST profiles for $\mathrm{H}_{\delta}$ of $10 \mathrm{mM}$ Arg in presence of $1 \mathrm{wt} \% \mathrm{TiO}_{2}$ and 1 wt $\%$ agarose on a $700 \mathrm{MHz}$ spectrometer with different B1 saturation fields $50 \mathrm{~Hz}, 100 \mathrm{~Hz}$, $150 \mathrm{~Hz}, 200 \mathrm{~Hz}, 250 \mathrm{~Hz}$, and $300 \mathrm{~Hz}$, and global fitting with a homogenous form of McConnell equations using Matlab code DESTfit, ${ }^{28,50}$ where a single spin in exchange between an observable free state $A$ with low $R_{2}$ and two bound states ( $B$ and $C$ ) with larger $R_{2}$ values $\left(A<==>\right.$ the mixture of $B$ and $C$ ). The cross-relaxation rate $\sigma_{A}$ between 
$\mathrm{H}_{\delta}$ (the observed signal) and $\mathrm{H}_{\mathrm{Y}}$ (coupled with $\mathrm{H}_{\delta}$ by cross relaxation) in free Arginine is assumed to be $-0.5 \mathrm{~s}^{-1}$, and cross-relaxation rate $\sigma_{B}$ between $\mathrm{H}_{\delta}$ and $\mathrm{H}_{Y}$ of Arginine bound on particle is assumed to be $-500 \mathrm{~s}^{-1}$, the output of global fitting: $R_{2}$ (strong binding) $=$ $38785 \pm 119 \mathrm{~s}^{-1}, R_{2}$ (weak binding) $=784 \pm 2 \mathrm{~s}^{-1}$ with population weights of 0.296 and 0.704 , respectively, $k_{\mathrm{off}}=36.9 \pm 0.1 \mathrm{~s}^{-1}, k_{\mathrm{on}}=2.9 \pm 0.0 \mathrm{~s}^{-1}$, total population of binding state $=0.073$, population of free state $=0.927$, population of strong binding state $=0.022$, population of weak binding state $=0.051$.

\section{Molecular Dynamics Simulations}

To investigate the nature and origins of structural diversity of adsorbed amino acids at liquid- $\mathrm{TiO}_{2} \mathrm{NP}$ interfaces, and the role played by surface-adsorbed water and surface hydroxyl groups in molecular adsorption, metadynamics was used to compute the binding free energy as a function of amino acid center of mass distance from the non-hydroxylated (Figure 7a) and hydroxylated (Figure 8a) surfaces for Arg and Lys, both of which show broadened DEST profiles in the presence of $\mathrm{TiO}_{2}$ NP's , as well as Asp, which does not show a broadened DEST profile in the presence of $\mathrm{TiO}_{2}$ NP's. Calculation of binding free energy is described in the Supporting Information. On both surfaces, we see that Arg is the strongest binder, followed by Lys, and finally Asp. On the non-hydroxylated surface (Figure 7a), there are two free energy minima for Lys and Arg, whereas Asp only shows a single minimum. Interestingly, on the hydroxylated surfaces, although the binding free energies for Arg and Lys are comparable to the non-hydroxylated surface, there is only a single minimum in the binding free energy profile. Asp binds with a lower free energy on the hydroxylated surface compared to the non-hydroxylated surface. The binding free energies for Arg, Lys, and Asp on the non-hydroxylated and hydroxylated surfaces are given in Table 1. 
(a)

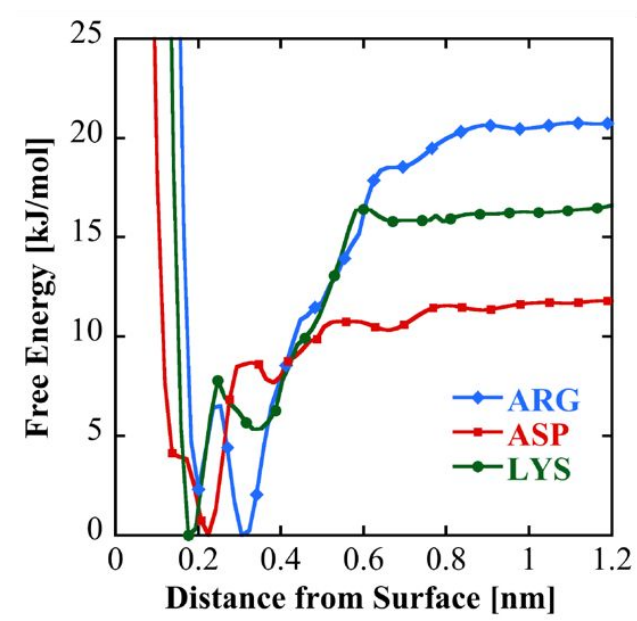

(b)

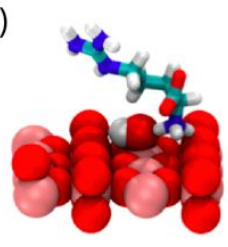

(d)

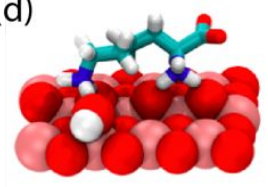

(f)

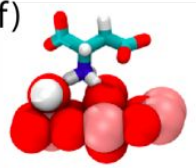

(c)

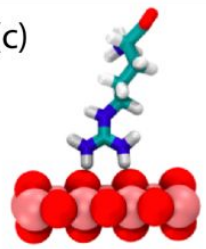

(e)

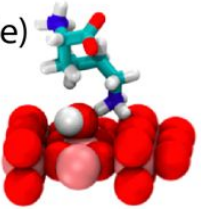

Figure 7: (a) Free energy profiles as a function of amino acid distance from the lowhydroxylated surface of $\mathrm{TiO}_{2}$. Dominant binding conformations represented by these curves are shown for arginine (b and c), lysine ( $d$ and e), and aspartic acid (f) on the lowhydroxylated surface.

(a)

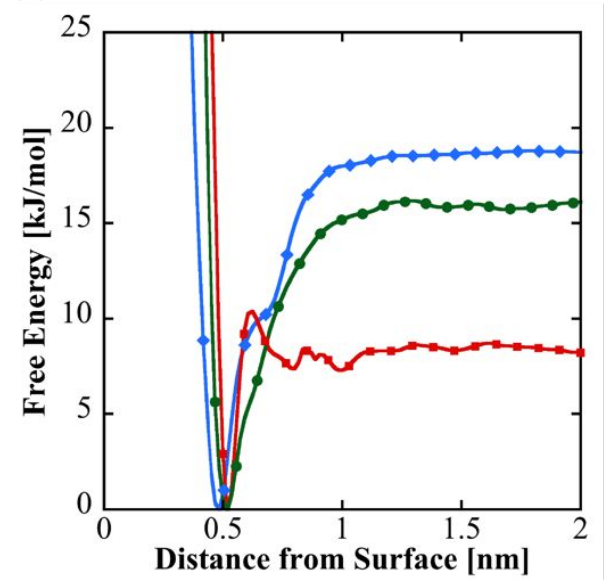

(b)

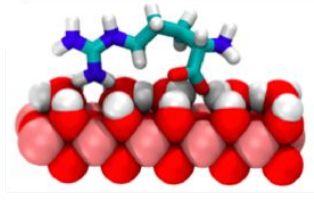

(c)

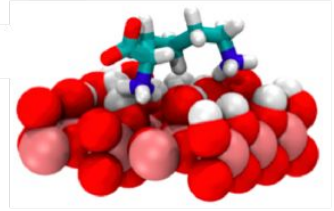

(d)

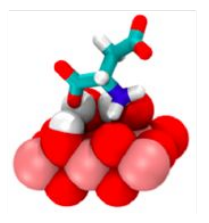

Figure 8: (a) Free energy as a function of amino acid distance from the hydroxylated surface of $\mathrm{TiO}_{2}$. Dominant binding conformations are shown for arginine (b), lysine (c), and aspartate (d) on the hydroxylated surface. Note: The peaks in Asp binding profile after 
$0.5 \mathrm{~nm}$ are within the thermal fluctuation $(2.5 \mathrm{~kJ} / \mathrm{mol})$ at $300 \mathrm{~K}$, and does not indicate a different binding mode

\begin{tabular}{|c|c|c|c|}
\hline & \multicolumn{2}{|c|}{$\begin{array}{c}\text { Binding Free Energy (kJ/mol) } \\
\text { Non-Hydroxylated Surface }\end{array}$} & \multirow{2}{*}{$\begin{array}{c}\text { Binding Free Energy (kJ/mol) } \\
\text { Hydroxylated Surface }\end{array}$} \\
\hline & Mode 1 (flat) & Mode 2 (extended) & -17 \\
\hline Arginine & -17 & -20 & -15 \\
\hline Lysine & -15 & -10 & -6 \\
\hline Aspartate & -10 & - & \\
\hline
\end{tabular}

Table 1: Binding free energies for the three amino acids on the two surfaces, in $\mathrm{kJ} / \mathrm{mol}$. The binding modes indicate binding poses (flat vs. extended) on the surface.

To understand the structural diversity of the amino acids on the surface, bound structures corresponding to the minima in the free energies for Arg (Figures 7 b-c, Figure 8b), Lys (Figures $7 \mathrm{~d}$-e, Figure 8c), and Asp (Figure 7f, Figure 8d) are shown. On the non-hydroxylated surface, Arg and Lys adopt distinct flat (Figures $7 \mathrm{~b}$ and $7 \mathrm{~d}$, respectively) and extended (Figures $7 \mathrm{c}$ and $7 \mathrm{e}$, respectively) conformations. The flat conformation for both (Figures $7 b$ and $7 d$ ) is mediated by the binding of the N-terminus, whereas the extended conformation occurs through the sidechain binding. On the hydroxylated surface, both amino acids adopt a flat conformation, mediated by the sidechain and C-terminus. This is in overall agreement with the features of the free energy curve in Figure 8. In contrast, Asp adopts a single conformation on both hydroxylated and nonhydroxylated surfaces. There is also good agreement with prior simulation studies, which report that binding occurs through backbone and side chain associations, ${ }^{54}$ as well as the fact that arginine binding is the strongest. 32,33

\section{The binding of amino acids with $\mathrm{TiO}_{2}$}


Study of the binding of amino acids to inorganic oxide NP surfaces, and $\mathrm{TiO}_{2} \mathrm{NP}$ surfaces in particular, is motivated by the fact that amino acids serve as models for the binding of more complicated polypeptides which are believed to interact with $\mathrm{TiO}_{2}$ surface hydroxyl groups via amino acid side chains. Numerous experimental studies, cited above, have characterized the binding affinity of amino acids to $\mathrm{TiO}_{2}$ NP surfaces. The present DEST NMR study, accompanied by a theoretical analysis of binding structures, not only characterizes the binding affinity of five amino acids (Arg, Lys, Leu, Asp, Ala) to $\mathrm{TiO}_{2}$ NP surfaces, but also the kinetics of binding. This is accomplished by simulation of the ${ }^{1} \mathrm{H}$ DEST saturation profiles through solution of the BlochMcConnell equations, which yields $\mathrm{R}_{2}$ values and populations as well as the kinetic constants that quantify exchange between the various free and bound species.

Kinetic information afforded by DEST simulations are useful both for interpreting the relationship between the free and multiple bound states as well as the degree to which interactions with the surface immobilizes the various bound molecular forms, where the transverse relaxation rate increases with the degree of immobilization of the molecule on the surface. It is interesting to compare the results of the DEST study to earlier studies of amino acids bound to $\mathrm{TiO}_{2}$ surfaces, and how kinetic information enhances our view of the binding mechanism. The ${ }^{1} \mathrm{H}$ DEST NMR studies indicate that the amino acids Leu, Ala, and Asp have only a single partly mobile bound form in exchange with the freely tumbling amino acid in bulk solution. The Asp result is in accord with an earlier Reflectance IR study which detected at least two bound forms of glutamic acid (Glu) on $\mathrm{TiO}_{2}$ surfaces, but a single bound form for Asp. ${ }^{26}$ The fact that Asp is weakly adsorbed onto the $\mathrm{TiO}_{2}$ NP surface is indicated by its narrow DEST profile which indicates the occurrence of reorientational motion even in the bound form. This weak binding is also in accord with the fact that at $\mathrm{pD} 7$ the net charge on Asp is negative and $\mathrm{TiO}_{2}$ has a negative surface charge. 
From ${ }^{1} \mathrm{H}$ DEST profiles of side chain protons however, both Arg and Lys have at least two bound forms on $\mathrm{TiO}_{2}$ NP surfaces, which display in both cases varying degrees of re-orientational motion as indicated by very different $\mathrm{R}_{2}$ values. An interesting conclusion of the DEST study of Arg involves the relationship between these weakly and strongly bound forms. In the DEST study of cholic acid and phenol to cerium oxide particles by Egner et al. ${ }^{31}$ analysis of DEST saturation profiles for cholic acid indicated only a single weakly bound form. However similar DEST studies of phenol indicated two bound forms: a weakly bound form displaying residual re-orientational motion, and a strongly bound form with a larger $\mathrm{R}_{2}$ relaxation rate indicating a greater degree of surface immobilization, a similar conclusion to that drawn by our DEST studies of Lys and Arg on $\mathrm{TiO}_{2} \mathrm{NP}$ surfaces. However, the kinetic information derived from the Egner et al study affords a different view of the binding mechanism than is given by the present study of amino acid binding to $\mathrm{TiO}_{2}$ NP's. With reference to the kinetic scheme in Figure 5, Egner et al. found a best fit to their DEST profile assuming phenol does not directly attach from the bulk solution, where it freely reorients, to the surface, where it is in an immobilized state. Egner et al. also found a finite rate of exchange between the weakly and strongly bound forms, indicating that phenol binds strongly to cerium oxide NP's via a weakly bound intermediate, which retains some reorientational degrees of freedom.

The DEST analysis of amino acid attachment to $\mathrm{TiO}_{2}$ NPs presented in this paper indicates a different mechanism of binding between basic amino acids Lys and Arg and rutile $\mathrm{TiO}_{2} \mathrm{NPs}_{\text {s }}$ than occurs between phenol and cerium oxide NPs. Again with reference to Figure 5, a model that best fits DEST profiles assumes for both Lys and Arg the absence of exchange between the weakly and strongly bound species, and that Lys and Arg in solution interact directly with NP surfaces to form populations of weakly and strongly bound forms. 
Because exchange between the two bound forms of Lys/Arg is absent in the best fit model to the DEST data, we cannot propose that the partially mobile forms of Lys or Arg are binding intermediates. So we turn to the surface chemistry of $\mathrm{TiO}_{2}$ as a possible source of variation in binding. It has long been known that dissociative adsorption of water onto rutile surfaces results in the formation of surface hydroxyl groups. ${ }^{51,52}$ Dissociative adsorption of water and subsequent formation of surface hydroxyl groups is known to be face sensitive. ${ }^{53}$ The surface chemistry observed for $\mathrm{TiO}_{2}$ NPs is also known to vary with crystal face and surface area. ${ }^{54}$ Therefore, the occurrence of bound Lys and Arg amino acids with different $R_{2}$ values may arise when amino acids attach to NP faces with different surface hydroxyl densities, resulting in different degrees of immobilization.

Molecular dynamics simulations were used to assess the degree to which the variation of surface water and surface hydroxyl groups on the $\mathrm{TiO}_{2} \mathrm{NP}$ surface might account for these multiple bound forms of Lys and Arg. MD simulations in this paper treated two extreme cases: complete absence and presence of surface hydroxyl groups. Under these conditions good qualitative agreement was achieved with ${ }^{1} \mathrm{H}$ DEST data. For example, on non-hydroxylated surfaces, Arg was found to occur in two forms distinguished by two modes of surface attachment: 1) attachment via the guanidinium group and 2) attachment via the amino group. In each case the opposite end of the amino acid was free to undergo restricted reorientational motions. We propose that these two forms would contribute to the so-called partly mobile bound form observed as a relatively narrow component of the DEST profile of the $\mathrm{H} \delta$ Arg proton. However, on hydroxylated $\mathrm{TiO}_{2} \mathrm{surfaces}_{\text {, }}$ Arg is attached via both its side chain and its amino group, essentially immobilizing the molecule or restricting its motions to a much greater degree than is observed on non-hydroxylated surfaces. This would account for the broad components observed in the ${ }^{1} \mathrm{H}$ DEST profiles of Arg and Lys. 
The binding mode of Arg on $\mathrm{TiO} 2$ predicted by MD calculations can be further studied and confirmed experimentally by analysis of relaxation data. For example, the binding mode of phenol on $\mathrm{CeO}_{2}$ NP's at atomic resolution was studied based on the analysis of ${ }^{13} \mathrm{C} R_{2}$ and $R_{1}$ of phenol in the bound state. ${ }^{55}$ Assuming the bound molecule undergoes rapid restricted rotation on the surface, the ${ }^{13} \mathrm{C} \mathrm{R}_{2}$ of phenol bound on $\mathrm{CeO}_{2}$ NP's shows a dependence on the angle $\theta$ between the $\mathrm{C}-\mathrm{H}$ bond vector and the axis of rotation, with maxima in $R_{2}$ occurring when the bond vector is parallel $\left(\theta=0^{\circ}\right)$ or antiparallel $\left(\theta=180^{\circ}\right)$ with the axis of rotation and minimum at angles $\theta=54.74^{\circ}$ and $125.26^{\circ}$. In contrast, the ${ }^{13} \mathrm{C} \mathrm{R}_{2}$ of phenol bound with $\mathrm{Pt} / \mathrm{CeO}_{2}$ is independent of the angle between the $\mathrm{C}-\mathrm{H}$ bond vector and the axis of rotation, and indicates that the phenol molecule is rigidly associated with $\mathrm{Pt} / \mathrm{CeO}_{2}$ particle. It will be interesting to similarly observe the position-specific relaxation of ${ }^{13} \mathrm{C}-{ }^{1} \mathrm{H}$ vectors in $\mathrm{Arg}$ bound on $\mathrm{TiO}_{2}$ by solution ${ }^{13} \mathrm{C}$ NMR to determine the orientation of $\mathrm{Arg}$ on $\mathrm{TiO}_{2}$ surface at atomic resolution. The results of such a study would further enhance the synergism between solution NMR and computational methods. 


\section{CONCLUSIONS}

This paper describes an application of ${ }^{1} \mathrm{H}$ DEST NMR techniques and Molecular Dynamics (MD) simulations to the study of the kinetics and thermodynamics of biomolecular adsorption onto rutile $\mathrm{TiO}_{2}$ surfaces. In this work basic amino acids are observed by ${ }^{1} \mathrm{H}$ DEST experiments to adsorb onto rutile $\mathrm{TiO}_{2}$ surfaces in multiple forms distinguished by varying degrees of mobility on the surface. Molecular Dynamics simulations indicate that variation in surface hydroxyl group group density may be partly responsible for these observations.

Although this study focused on the adsorption of monomeric amino acids onto $\mathrm{TiO}_{2} \mathrm{NP}$ surfaces, ${ }^{1} \mathrm{H}$ DEST will be useful in general for studying the effect of surface heterogeneity in the binding of larger peptides and proteins to inorganic oxide surfaces. For example, a widely studied surface-binding peptide is the 12 amino acid peptide aptamer i.e. TBP-1 (RKLPDAPGMHTW) developed by Sano and coworkers used peptide phage display methodology which electrostatically interacts with the oxidized surface of $\mathrm{Ti}^{16-18}$. The $\mathrm{N}$-terminal heaxapeptide RKLPDA is sufficient for $\mathrm{TiO}_{2}$. Even in the case of this relatively small peptide, diverse views have been reported for its interactions with $\mathrm{TiO}_{2}$ surfaces. Sano and coworkers proposed that the positively charged side chain of $\mathrm{R} 1$ binds to acidic $\left(-\mathrm{O}^{-}\right)$hydroxyl sites while the negatively charged side chain of D5 binds to basic $\left(-\mathrm{OH}_{2}{ }^{+}\right)$hydroxyl sites. ${ }^{16}$ This binding model was supported by a subsequent adhesion force analysis using AFM. ${ }^{18}$ In contrast an NMR study by Suzuki et.al. of TBP-6 bound to $\mathrm{TiO}_{2}$ NP's concluded that the peptide interacts with the NP surface via the side chains of R1 and K2, while the C-terminal amino acids do not display interactions with the surface. ${ }^{56}$

Based on the results of this study, it is possible that the results of both of these studies are valid. The structure observed by Suzuki et al. may be a partly mobile form with a small $\mathrm{R}_{2}$, while the fully immobilized or dark state form reported by Sano and coworkers possesses a much larger 
$\mathrm{R}_{2}$. This situation, which may result from heterogeneity of the NP surface chemistry, could be identified by a ${ }^{1} \mathrm{H}$ DEST study. We will report such a study in the near future.

Supporting Information.

Well Tempered Metadynamics. ${ }^{1} \mathrm{H}$ NMR spectra of $10 \mathrm{mM}$ amino acids Lysine, Leucine,

Aspartic acid, and Alanine, in the absence of gel, in the presence of gel, and in the

presence of gel and $1 \mathrm{wt} \% \mathrm{TiO}_{2} .{ }^{1} \mathrm{H}$ DEST profiles for $\mathrm{H}_{\varepsilon}$ of $10 \mathrm{mM}$ Lysine, Leucine,

Aspartate, and Alanine in the absence of gel, in the presence of gel, and in the

ACS Paragon Plus Environment 
presence of gel and $1 \mathrm{wt} \% \mathrm{TiO}_{2}$. Deconvoluted ${ }^{1} \mathrm{H}$ DEST profiles for $\mathrm{H}_{\varepsilon}$ of $10 \mathrm{mM}$ Lys as a function of $\mathrm{B}_{1}$ field. Simulations of Lys and $\mathrm{Arg}{ }^{1} \mathrm{H}$ DEST profiles using global fitting with a homogenous form of McConnell equations using DESTfit. Fitting parameters for Z-spectra od Arg an Lys. Summary of kinetic parameters for the binding of $10 \mathrm{mM}$ Arg and Lys with $\mathrm{TiO}_{2}$ using DESTfit. Simulation setup for the arginine (Arg), lysine (Lys), and aspartate (Asp) on the four titania surfaces.

Acknowledgements.

GPD acknowledges National Institutes of Health Grant R21 A126113, NASA grant NNX17AK86G (Exobiology), and National Science Foundation Grant MCB-1715123. GPD also acknowledges support from collaboration with the University of Oslo through the Research Council of Norway grant 231530. 


\section{REFERENCES}

(1) Verket, A.; Tiainen, H.; Haugen, H. J.; Lyngstadaas, S. P.; Nilsen, O.; Reseland, J. E. Enhanced osteoblast differentiation on scaffolds coated with $\mathrm{TiO}_{2}$ compared to $\mathrm{SiO}_{2}$ and CaP coatings. Biointerphases 2012, 7, 36.

(2) Chen, Q. Z.; Thompson, I. D.; Boccaccini, A. R. 4555 Bioglass $^{\circledR}$-derived glassceramic scaffolds for bone tissue engineering. Biomaterials 2006, 27, 2414-2425.

(3) Yuan, H.; de Bruijn, J. D.; Zhang, X.; van Blitterswijk, C. A.; de. Groot, K. Bone induction by porous glass ceramic made from bioglass ${ }^{\circledR}(45 S 5)$. J. Biomed. Mater. Res. 2001, 58, 270-276.

(4) Forsgren, J.; Svahn, F.; Jarmar, T.; Engqvist, H. Formation and adhesion of biomimetic hydroxyapatite deposited on titanium substrates. Acta Biomater. 2007, 3, 980-984.

(5) Uchida, M.; Kim, H.; Kokubo, T.; Fujibayashi, S.; Nakamura,T. Structural dependence of apatite formation on titania gels in a simulated body fluid. $J$. Biomed. Mater. Res. Part A 2003, 64, 164-170.

(6) Tiainen, H.; Wohlfahrt, J. C.; Verket, A.; Lyngstadaas, S. P.; Haugen, H. J. Bone formation in $\mathrm{TiO}_{2}$ bone scaffolds in extraction sockets of minipigs. Acta Biomater. 2012, 8, 2384-2391.

(7) Haugen, H.; Will, J.; Köhler, A.; Hopfner, U.; Aigner, J.; Wintermantel, E. Ceramic $\mathrm{TiO}_{2}$-foams: Characterisation of a potential scaffold. J. Eur. Ceram. Soc. 2004, 24, $661-668$.

(8) Tiainen, H.; Lyngstadaas, S. P.; Ellingsen, J. E.; Haugen, H. J. Ultra-porous titanium oxide scaffold with high compressive strength. J. Mater. Sci. Mater. Med. 2010, 21, 2783-2792. 
(9) Jones, F. H. Teeth and bones: Applications of surface science to dental materials and related biomaterials. Surf. Sci. Rep. 2001, 42, 75-205.

(10) Linsebigler, A. L.; Lu, G.; Yates, J. T. Photocatalysis on $\mathrm{TiO}_{2}$ surfaces: Principles, mechanisms, and selected results. Chem. Rev. 1995, 95, 735-758.

(11) Varghese, O. K.; Grimes, C. A. Metal oxide nanoarchitectures for environmental sensing. J. Nanosci. Nanotechnol. 2003, 3, 277-293.

(12) Wintermantel, E.; Eckert, K.-L.; Huang, N.-P.; Textor, M.; Brunette, D. M. Titanium ceramics for cell-carriers and for medical applications; Springer Berlin Heidelberg, 2001; pp 649-671.

(13) Vallee, A.; Humblot, V.; Pradier, C. Peptide interactions with metal and oxide surfaces. Acc. Chem. Res. 2010, 43, 1297-1306.

(14) Buckle, E. L.; Lum, J. S.; Roehrich, A. M.; Stote, R. E.; Vandermoon, B.; Dracinsky, M.; Filocamo, S. F.; Drobny, G. P. Serine-lysine peptides as mediators for the production of titanium dioxide: investigating the effects of primary and secondary structures using solid-state NMR spectroscopy and DFT calculations. J. Phys. Chem. B 2018, 122, 4708-4718.

(15) Buckle, E. L.; Prakash, A.; Bonomi, M.; Sampath, J.; Pfaendtner, J.; Drobny, G. P. Solid-state NMR and MD study of the structure of the statherin mutant SNa15 on mineral surfaces. J. Am. Chem. Soc. 2019, 141, 1998-2011.

(16) Sano, K.; Shiba, K. A hexapeptide motif that electrostatically binds to the surface of titanium. J. Am. Chem. Soc. 2003, 125, 14234-14235.

(17) Sano, K.; Sasaki, H.; Shiba, K. Specificity and biomineralization activities of TiBinding Peptide-1 (TBP-1). Langmuir 2005, 21, 3090-3095. 
(18) Hayashi, T.; Sano, K.-I.; Shiba, K.; Kumashiro, Y.; Iwahori, K.; Yamashita, I.; Hara, M. Mechanism underlying specificity of proteins targeting inorganic materials. Nano Lett. 2006, 6, 515-519.

(19) Chen, Z.; Shen, Y. R.; Somorjai, G. A. Studies of polymer surfaces by sum frequency generation vibrational spectroscopy. Annu. Rev. Phys. Chem. 2002, 53, 437-465.

(20) Weidner, T.; Castner, D. G. SFG analysis of surface bound proteins: A route towards structure determination. Phys. Chem. Chem. Phys. 2013, 15, 1251612524.

(21) Shaw, W. J. Solid-state NMR studies of proteins immobilized on inorganic surfaces. Solid State Nucl. Magn. Reson. 2015, 70, 1-14.

(22) Zhang, Y.; Xu, H.; Parsons, A. M.; Casabianca L. B. Examining binding to nanoparticle surfaces using saturation transfer difference (STD)-NMR spectroscopy. J. Phys. Chem. C 2017, 121, 24678-24686.

(23) Okazaki, S.; Aoki, T.; Koichi, T. The adsorption of basic $\alpha$-amino acids in an aqueous solution by titanium (IV) oxide. Bull. Chem. Soc. Jpn. 1981, 54, 15951599.

(24) Roddick-Lanzilotta, A. D.; Connor, P. A.; McQuillan, A. J. An in situ infrared spectroscopic study of the adsorption of lysine to $\mathrm{TiO}_{2}$ from an aqueous solution. Langmuir 1998, 14, 6479-6484.

(25) Mudunkotuwa, I. A.; Grassian, V. H. Histidine adsorption on tio 2 nanoparticles: An integrated spectroscopic, thermodynamic, and molecular-based approach toward understanding nano-bio interactions. Langmuir 2014, 30, 8751-8760.

(26) Roddick-Lanzilotta, A. D.; McQuillan, A. J. An in situ infrared spectroscopic study of glutamic acid and of aspartic acid adsorbed on $\mathrm{TiO}_{2}$ : Implications for the biocompatibility of titanium. J. Colloid Interf. Sci. 2000, 227, 48-54. 
(27) Shchelokov, A.; Palko, N.; Potemkin, V.; Grishina, M.; Morozov,R.; Korina, E.; Uchaev, D.; Krivtsov, I.; Bol'shakov, O. Adsorption of native amino acids on nanocrystalline $\mathrm{TiO}_{2}$ : Physical chemistry, QSPR, and theoretical modeling. Langmuir 2019, 35, 538-550.

(28) Fawzi, N. L.; Ying, J.; Torchia, D. A.; Clore, G. M. Kinetics of amyloid $\beta$ monomerto-oligomer exchange by NMR relaxation. J. Am. Chem. Soc. 2010, 132, 99489951.

(29) Fawzi, N. L.; Ying, J.; Ghirlando, R.; Torchia, D. A.; Clore, G. M. Atomic-resolution dynamics on the surface of amyloid- $\beta$ protofibrils probed by solution NMR. Nature 2011, 480, 268-272.

(30) Fawzi, N. L.; Libich, D. S.; Ying, J.; Tugarinov, V.; Clore, G. M. Characterizing methyl-bearing side chain contacts and dynamics mediating amyloid $\beta$ protofibril

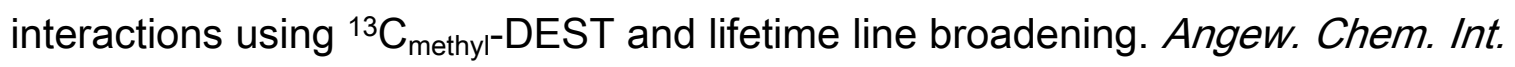
Ed. 2014, 53, 10345-10349.

(31) Egner, T. K.; Naik, P.; Nelson, N. C.; Slowing, I. I.; Venditti, V. Mechanistic insight into nanoparticle surface adsorption by solution NMR spectroscopy in an aqueous gel. Angew. Chem. Int. Ed. 2017, 129, 9934 -9938.

(32) Yazdanyar, A.; Aschauer, U.; Bowen, P. Adsorption free energy of single amino acids at the rutile (110)/water interface studied by well-tempered metadynamics. J. Phys. Chem. C 2018, 122, 11355-11363.

(33) Kang, Y.; Li, X.; Tu, Y.; Wang, Q.; Ågren, H. On the mechanism of protein adsorption onto hydroxylated and nonhydroxylated $\mathrm{TiO}_{2}$ surfaces. J. Phys. Chem. C 2010, 114, $14496-14502$.

(34) Brandt, E. G.; Lyubartsev, A. P. Molecular dynamics simulations of adsorption of amino acid side chain analogues and a titanium binding peptide on the $\mathrm{TiO}_{2}(100)$ surface. $J$. Phys. Chem. C 2015, 119, 18126-18139.

(35) Skelton, A. A.; Liang, T.; Walsh, T. R. Interplay of sequence, conformation, and binding at the peptide-titania interface as mediated by water. ACS Appl. Mater. Interfaces 2009, $1,1482-1491$.

(36) Sultan, A. M.; Hughes, Z. E.; Walsh, T. R. Binding affinities of amino acid analogues at the charged aqueous titania interface: implications for titania-binding peptides. Langmuir 2014, 30, 13321-13329. 
(37) Zhou, I. Y.; Wang, E.; Cheung, J. S.; Zhang, X.; Fulci, G.; Sun, P. Z. Quantitative chemical exchange saturation transfer (CEST) MRI of glioma using Image Downsampling Expedited Adaptive Least-squares (IDEAL) fitting. Sci. Rep. 2017, 7,84 .

(38) Cai, K.; Singh, A.; Poptani, H.; Li, W.; Yang, S.; Lu, Y.; Hariharan, H.; Zhou, X. J.; Reddy, R. CEST signal at 2ppm (CEST@2ppm) from Z-spectral fitting correlates with creatine distribution in brain tumor. NMR Biomed. 2015, 28, 1-8.

(39) Zaiss, M.; Windschuh, J.; Paech, D.; Meissner, J.-E.; Burth, S.; Schmitt, B.; Kickingereder, P.; Wiestler, B.; Wick, W.; Bendszus, M.; Schlemmer, H.-P.; Ladd, M. E.; Bachert, P.; Radbruch, A. Relaxation-compensated CEST-MRI of the human brain at $7 \mathrm{~T}$ : Unbiased insight into NOE and amide signal changes in human glioblastoma. Neurolmage 2015, 112, 180-188.

(40) Zhang, X.-Y.; Wang, F.; Afzal, A.; Xu, J.; Gore, J. C.; Gochberg, D. F.; Zu, Z. A new NOE-mediated MT signal at around $-1.6 \mathrm{ppm}$ for detecting ischemic stroke in rat brain. Magn. Reson. Imaging 2016, 34, 1100-1106.

(41) Zhang, X.; Wang, F.; Jin, T.; Xu, J.; Xie, J.; Gochberg, D. F.; Gore, J. C.; Zu, Z. MR imaging of a novel NOE-mediated magnetization transfer with water in rat brain at 9.4 T. Magn. Reson. Med. 2017, 78, 588-597.

(42) Předota, M.; Bandura, A. V.; Cummings, P. T.; Kubicki, J. D.; Wesolowski, D. J.; Chialvo, A. A.; Machesky, M. L. Electric double layer at the rutile (110) surface. 1. Structure of surfaces and interfacial water from molecular dynamics by use of ab initio potentials. J. Phys. Chem. B 2004, 108, 12049-12060.

(43) Huang, J.; MacKerell Jr, A. D. CHARMM36 all-atom additive protein force field: Validation based on comparison to NMR data. J. Comput. Chem. 2013, 34, 21352145. 
(44) Bussi, G.; Donadio, D.; Parrinello, M. Canonical sampling through velocity rescaling. J. Chem. Phys. 2007, 126, 014101.

(45) Parrinello, M.; Rahman, A. Polymorphic transitions in single crystals: A new molecular dynamics method. J. Appl. Phys. 1981, 52, 7182.

(46) Barducci, A.; Bussi, G.; Parrinello, M. Well-tempered metadynamics: A smoothly converging and tunable free-energy method. Phys. Rev. Lett. 2008, 100, 020603.

(47) Abraham, M. J.; Murtola, T.; Schulz, R.; Páll, S.; Smith, J. C.; Hess, B.; Lindahl, E. GROMACS: High performance molecular simulations through multi-level parallelism from laptops to supercomputers. SoftwareX, 2015, 1-2, 19-25.

(48) Tribello, G. A.; Bonomi, M.; Branduardi, D.; Camilloni, C.; Bussi, G. PLUMED 2: New feathers for an old bird. Comput. Phys. Commun. 2014, 185, 604-613.

(49) Helgstrand, M.; Härd, T.; Allard, P. Simulations of NMR pulse sequences during equilibrium and non-equilibrium chemical exchange. J. Biomol. NMR 2000, 18, 49-63.

(50) Fawzi, N. L.; Ying, J.; Torchia, D. A.; Clore, G. M. Probing exchange kinetics and atomic resolution dynamics in high-molecular-weight complexes using dark-state exchange saturation transfer NMR spectroscopy. Nat. Protoc. 2012, 7, 15231533.

(51) Connor, P. A.; Dobson, K. D.; McQuillan, A. J. Infrared spectroscopy of the $\mathrm{TiO}_{2}$ /aqueous solution interface. Langmuir 1999, 15, 2402-2408.

(52) Henderson, M. A. The interaction of water with solid surfaces: fundamental aspects revisited. Surf. Sci. Rep. 2002, 46, 1-308.

(53) Henderson, M. A. Structural sensitivity in the dissociation of water on $\mathrm{TiO}_{2}$ single-crystal surfaces. Langmuir 1996, 12, 5093-5098.

(54) Bolis,V.; Busco, C.; Ciarletta, M.; Distasi, C.; Erriquez, J.; Fenoglio, I.; Livraghi, S.; Morel, $\mathrm{S}$. Hydrophilic/hydrophobic features of $\mathrm{TiO}_{2}$ nanoparticles as a function of crystal phase, 
surface area and coating, in relation to their potential toxicity in peripheral nervous system. J. Colloid Interface Sci.2012, 369, 28-39.

(55) Egner, T. K.; Naik, P.; An, Y.; Venkatesh, A.; Rossini, A. J.; Slowing, I. I.; Venditti, V. 'Surface Contrast' NMR reveals non-innocent role of support in $\mathrm{Pd} / \mathrm{CeO}_{2}$ catalyzed phenol hydrogenation. Chem CatChem 2020, DOI: 10.1002/cctc.202000608.

(56) Suzuki, Y.; Shindo, H.; Asakura, T. Structure and dynamic properties of a Ti-binding peptide bound to $\mathrm{TiO}_{2}$ nanoparticles as accessed by ${ }^{1} \mathrm{H}$ NMR spectroscopy. J. Phys. Chem. B 2016, 120, 4600-4607. 


\section{For Table of Contents Only:}
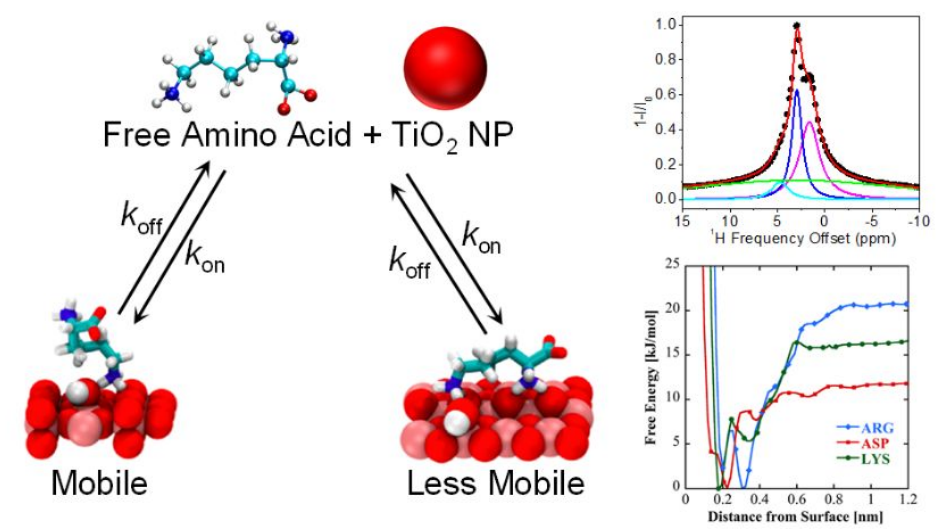